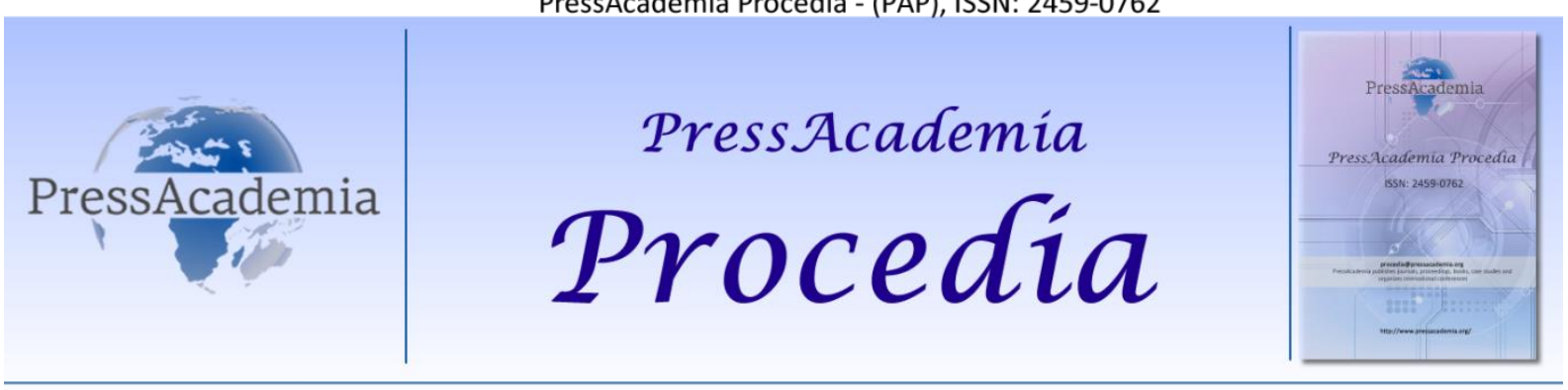

Global Business Research Congress (GBRC), May 24-25, 2017, Istanbul, Turkey.

\title{
DETERMINING IMPORTANCE LEVELS OF INTERN STUDENT ACCEPTANCE CRITERIA BY SWARA METHOD: A RESEARCH ON HUMAN RESOURCES ASSOCIATE STUDENTS
}

\author{
DOI: 10.17261/Pressacademia.2017.431 \\ PAP-GBRC-V.3-2017(46)-p.447-456
}

\author{
Engin Cakir ${ }^{1}$, Sinasi Yaylagul ${ }^{2}$ \\ ${ }^{1}$ Adnan Menderes University. engincakir@adu.edu.tr \\ ${ }^{2}$ Adnan Menderes University. sinasi.yaylagul@adu.edu.tr
}

\section{To cite this document}

Cakir E. and S.Yaylagul, (2017). Determining importance levels of intern student acceptance criteria by SWARA method: a research on human resources associate students. PressAcademia Procedia (PAP), V.3, p.447-456

Permemant link to this document: http://doi.org/10.17261/Pressacademia.2017.431

Copyright: Published by PressAcademia and limited licenced re-use rights only.

\begin{abstract}
This study is to determine the weight of the criteria, which are important for the students, studying in Human Resources Management Associate Degree Program of the universities, to be accepted as intern in Human Resources department of companies during their compulsory summer internships, by using SWARA method and thus to be guiding for what criteria should be focused in the education of the students who want to do their internships in the companies which are pioneers in the sector. The study was conducted with mid- and lower level managers (decision makers) in the Human Resources department having a role in the pre-evaluation of the internship applications of the companies which are in leading position in their sectors. In the study, firstly, each decision maker ranked the criteria by placing the most important one as the first, and then they revealed the significance levels among the criteria. Finally, the significance levels (weights) of the criteria were determined as a result of the calculation of the data obtained from the decision makers by using the SWARA method. According to the results of SWARM method, the most important criterion is "the desire to practice internship of the intern candidate", the second most important criterion is "the suitability to work of the intern candidate" and third most important criterion is "general appearance / first impression of the intern candidate".
\end{abstract}

Keywords: Intern Selection Criteria, SWARA Method, Human Resources, Intern

JEL Codes: C44, D70, M12

\section{IŞLETMELERIN STAJYER ÖĞRENCI KABUL KRITERLERINE ILIŞKIN ÖNEM DÜZEYLERINNIN SWARA YÖNTEMi ILE BELIRLENMESi: INSAN KAYNAKLARI ÖNLISANS ÖĞRENCILERi ÜZERINE BíR ARAŞTIRMA}

\section{ÖZET}

Üniversitelerin İnsan Kaynakları Yönetimi Önlisans Programında okumakta olan öğrencilerin, zorunlu yaz stajlarında şirketlerin İnsan Kaynakları biriminde stajyer olarak kabul edilmeleri için önem arz eden kriterlerin ağırlıklarının SWARA yöntemi ile belirlenmesi ve böylece sektörde öncü konumda olan şirketlerde staj yapmak isteyen öğrencilerin eğitimlerinde hangi kriterlere ağırlık vermesi gerektiği konusunda yol göstermektir. Uygulama, sektörlerinde lider konumda olan şirketlerin stajyer başvurularının ön değerlendirmesinde rol alan İnsan Kaynakları departmanındaki görevli yöneticiler (Uzmanlar) ile gerçekleştirilmiştir. Çalışmada öncelikle her bir uzman, kriterleri en önemlisi ilk sırada olacak şekilde sıralamış, daha sonra kriterler arası önem düzeylerini ortaya koymuştur. Son olarak, uzmanlardan elde edilen verilerin SWARA yöntemi ile hesaplanması sonucunda kriterlerin önem düzeyleri (ağılıkları) belirlenmiştir. SWARA yöntemi ile yapılan değerlendirme sonucuna göre en önemli kriterin "stajyer adayının staj yapma isteğindeki davranış" olduğu; ikinci en önemli kriterin "stajyer adayının işe uygunluğu" ve üçüncü en önemli kriterin ise "stajyer adayının genel görünümü/ilk izlenimi" olduğu tespit edilmiştir.

Anahtar Kelimeler: Personel Seçim Kriterleri, SWARA Yöntemi, İnsan Kaynakları, Stajyer JEL Kodları: C44, D70, M12 


\section{GiRiş}

Üniversitelerin eğitim öğretim yönetmeliklerinde senato kararı ile kararlaştırdıkları, önlisans öğrencilerine zorunlu stajdan başarılı olmayı mezuniyet şartı olarak getirmekte ve 3308 sayılı Mesleki Eğitim Kanunu da staj ile ilgili uygulamalara ait düzenlemeleri içermektedir. Türkiye genelinde 2015-2016 akademik yılında, 182 devlet ve vakıf üniversitesi bulunmakta, bu yükseköğretim kurumlarında 2.285.406 önlisans olmak üzere toplam 6.689.185 öğrenci kayıtlı bulunmaktadır. Önlisans öğrencilerinin bir milyonu geçkini birinci ve ikinci (örgün) öğretim programlarında eğitim almaktadır.

Önlisans öğrencilerinin özellikle ilk yılsonundaki yaz döneminde staj yapmak istemesi, hem teorik bilgi konusunda yetersiz olmaları hem de iş arama ile ilgili somut bir ihtiyacın açığa çıkmamış olması nedeniyle staj yeri seçimi ve staja kabul edilme konusunda bir takım engeller açığa çıkarmaktadır. Özellikle öğrencilerin, kendi alanlarında staj yapmaları stajın ana amacını oluşturan teorik bilginin, uygulamaya transfer edilerek iş başında pekiştirilmesini sağlayacaktır.

Öğrencilerin elektronik mecralarda ve birebir başvuruları ile staja başvurusu yaptıkları kurumların, bu öğrencilerin staja kabul edilmesinde hangi kriterleri daha önemli gördüğü konusunda açıklık getirilmesi, öğrencilerin başvuru öncesi kendilerini bu kriterlerde yeterli getirmeleri açısından önem arz etmektedir. Böylece özel sektör işletmelerinin talepleri doğrultusunda yükseköğrenim gören öğrencilere doğru danışmanlık hizmeti verilerek, staja kabul edilme ihtimalleri arttırılacaktır.

Bu çalışmada staja kabul kriterlerinin önem düzeylerinin belirlenmesi amacıyla çok kriterli karar verme yöntemlerinden SWARA yönteminden yararlanılmıştır. Yöntem, herkes tarafından kolaylıkla yapılabilir olması nedeniyle tercih edilmiştir. Sektörlerinde (telekomünikasyon, sağlık, inşaat malzemeleri vb.) öncü konumda bulunan kurumlarda, stajyer öğrenci seçiminden sorumlu insan kaynakları çalışanlarına (insan kaynakları uzman yardımcısı veya insan kaynakları memuru), stajyer öğrenci kabul kriterlerini sıralamaları, ardından da sıralama yaptıkları kriterlerin göreli önem düzeylerini belirlemeleri istenmiştir. Tüm karar vericilerin kriterler için atadığı değerlerin ortalaması alınarak, nihai kriter ağırlıklarına ulaşılmıştır.

\section{LITERATÜR INCELEMESI}

\subsection{Stajyer ve Staj Kavramı}

Türk Dil Kurumu stajyer için kelime anlamı "Staj yapan kimse", staj ise "Herhangi bir meslek edinecek olan kimsenin geçirdiği uygulamalı öğrenme dönemi" ve "Bir kimsenin, meslek bilgisini artırmak için bir kurumun bir veya birçok bölümünde çalışarak geçirdiği dönem” olarak tanımlanmaktadır (Türk Dil Kurumu, 2017).

Eğitim kurumlarında öğrencilerin, aldıkları bilgi, beceri, davranış, bilişsel stratejiler vb. öğrendikleri teorik bilgilerin, işlerine aktarılması ve uygulanma konusunda devamlılık sergilemeleri önem arz etmektedir. Bir işyerindeki çalışana aldığı eğitimi uygulatarak aktarımının sağlanması ne yazık ki öğrenciler için aynı şekilde gerçekleştirilememektedir. Bu nedenle de işbaşında öğrenme yöntemlerinden staj, öğrenciler için en uygun eğitimin aktarılması (transferi) yöntemi olarak kabul görmektedir.

Staj Yoluyla Eğitim: Staj, iş görenlerin belli bir konuda bilgi sahibi olabilmeleri ve tecrübe kazanmaları için işletme içinde veya dışın da belli bir görevde bulundurulmalarıdır. Staj, iş görenlere ileride yapacakları işlere ilişkin çalıma ortamlarını tanıtma, işleri öğrenme mesleki sorumluluk taşıma gibi yararlar sağlamaktadır. Örnek olarak yeni mezun bir endüstri mühendisi alınabilir. Bu kişi kendisine yabancı bulunan endüstriyel yaşamın belirli gerçeklerinin öğrenmek için bir işletmeye gönderilir orada iş ortamının öğrenilmesi sağlanır (Yılmazer, 2013: 139).

Herhangi bir meslek edinecek olan kimsenin geçirdiği uygulamalı öğrenme dönemi ve bu kimsenin, meslek bilgisini artırmak için bir kurumun bir veya birçok bölümünde çalışarak geçirdiği eğitim dönemidir. Staj yoluyla eğitimin şu yararları vardır (Baraz, 2009: 102).

- Staj döneminde öğrenciler (stajyerler), ileride çalışmayı düşündükleri alanlar hakkında bilgi sahibi olarak, ilgi duydukları konulan ya da bölümleri tespit ederek gelecekleri için daha iyi planlar yaparlar.

- Akademik bilgiler, çalışma ortamında gözleme dayalı pratik uygulamalara dönüşürken, daha akılda kalıcı olur.

- $\quad$ ileride meslek yaşamlarında karşılaşabilecekleri sorunları mantık ve bilgi çerçevesinde en uygun şekilde ve en kısa zamanda çözebilmeleri için yeni beceriler, pratiklik ve vizyon kazanırlar.

- Takım çalışmasının önemini kavrarlar. Verilen görevi zamanında en iyi şekilde tamamlamaya çalışarak sorumluluk duyguları gelişir; kendilerine olan güvenleri ve cesaretleri artar.

- Staj, öğrencilerin işverenlerle iletişim kurmalarını sağlayan, edindikleri referanslarla mezun olduktan sonra iş bulma imkanlarını artıran çok önemli bir fırsattır. 
Çıraklık aşaması bilgilerin içselleştirildiği aşamadır. Bu aşamanın sonunda elde edilen bilgi ve beceriler rehberlik ve gözetim desteği olmadan kullanılmaya başlanır. Bunu yaparken doğrulayıcı ve geliştirici geribildirim çok önemlidir (Şimşek, 2012: 174).

\subsection{Sayılı Eğitim Kanununda Staj ve Stajyer Kavramı}

Bu Kanunun amacı; çırak, kalfa ve ustaların eğitimi ile okullarda, yükseköğretim kurumlarında ve işletmelerde yapılacak mesleki eğitime ilişkin esasları düzenlemektir (Mesleki Eğitim Kanunu [MEK], 1986: madde 1).

"Öğrenci", işletmelerde, mesleki ve teknik eğitim okul ve kurumlarında örgün eğitim görenleri ifade eder (MEK, 1986: madde $3 / d$ ).

“Mesleki ve Teknik Eğitim Okul ve Kurumları”, mesleki ve teknik eğitim alanında, diplomaya götüren orta öğretim kurumları ve mesleki ve teknik eğitim yapan yükseköğretim kurumları ile belge ve sertifika programlarının uygulandığı her tür ve derecedeki örgün ve yaygın eğitim-öğretim kurumlarını ifade eder (MEK, 1986: madde 3/j).

"Staj", öğrencilerin öğretim programlarıyla kazandırılması öngörülen mesleki bilgi, beceri, tutum ve davranışlarını geliştirmeleri, sektörü tanımaları, iş hayatına uyumları, gerçek üretim ve hizmet ortamında yetişmeleri amacıyla işletmede yaptıkları mesleki çalışmayı ifade eder (MEK, 1986: madde 3/r).

Staj yapan yükseköğretim kurumu öğrencisinin, bu kanun kapsamında ücret karşılığı çalışan haline gelmiş olması, seçim sürecinde sözleşme öğrencilere karşı daha seçici yaklaşmayı gerekli kılan etkenlerden biri olarak karşımıza çıkmaktadır.

Aday çırak ve çıraklar ile işletmelerde mesleki eğitim gören, staj veya tamamlayıcı eğitime devam eden öğrencilere işletmeler tarafından ödenecek ücret ve bu ücretlerdeki artışlar, düzenlenecek sözleşme ile tespit edilir. Ancak, işletmelerde mesleki eğitim gören öğrenciler ile mesleki ve teknik ortaöğretim okul ve kurumlarında staj veya tamamlayıcı eğitim gören öğrencilere asgari ücretin net tutarının; yirmi ve üzerinde personel çalıştıran işyerlerinde yüzde otuzundan, yirmiden az personel çalıştıran işyerlerinde yüzde on beşinden, aday çırak ve çırağa yaşına uygun asgari ücretin yüzde otuzundan aşağı ücret ödenemez. Bu amaçla kamu kurum ve kuruluşları gerekli tedbirleri alır. Staj yapacak işletme bulunamaması nedeniyle stajını okulda yapan ortaöğretim öğrencilerinin yaptıkları stajlar bu fıkra hükmü kapsamı dışındadır (MEK, 1986: madde 25/1).

\subsection{Sayılı İş Sağlığı ve Güvenliği Kanununda Staj ve Stajyer Kanunu}

Bu Kanun; kamu ve özel sektöre ait bütün işlere ve işyerlerine, bu işyerlerinin işverenleri ile işveren vekillerine, çırak ve stajyerler de dâhil olmak üzere tüm çalışanlarına faaliyet konularına bakılmaksızın uygulanır (İş Sağlığı ve Güvenliği Kanunu [iSGK], 2012: madde 2).

Çalışan: Kendi özel kanunlarındaki statülerine bakılmaksızın kamu veya özel işyerlerinde istihdam edilen gerçek kişiyi ifade eder (iSGK, 2012: madde 3/b).

Ancak stajyerlerin varlığı, işverenlerin yerine getirmesi gereken iş sağlığı ve güvenliği hizmetleri konusunda, stajyerlerin birer çalışan olarak korunması dışında ayrıca bir külfet getirmemektedir. Ancak buradaki en önemli ibare, stajyerlerin de tam süreli çalışanlar gibi birer çalışan olarak görülmesidir.

\subsection{Sayılı Sosyal Sigortalar ve Genel Sağlık Sigortası Kanununda Staj ve Stajyer Kavramı}

5/6/1986 tarihli ve 3308 sayılı Meslekî Eğitim Kanununda belirtilen aday çırak, çırak ve işletmelerde meslekî eğitim gören öğrenciler hakkında iş kazası ve meslek hastalığı ile hastalık sigortası; meslek liselerinde okumakta iken veya yüksek öğrenimleri sırasında staja tabi tutulan öğrenciler, kamu kurum ve kuruluşları tarafından desteklenen projelerde görevli bursiyerler ile 2547 sayılı Yükseköğretim Kanununun $46 \mathrm{ncı}$ maddesine tabi olarak kısmi zamanlı çalıştırılan öğrencilerden aylık prime esas kazanç tutarı, 82 nci maddeye göre belirlenen günlük prime esas kazanç alt sınırının otuz katından fazla olmayanlar hakkında ise iş kazası ve meslek hastalığı sigortası uygulanır. Bu bentte sayılanlar, 4 üncü maddenin birinci fıkrasının (a) bendi kapsamında sigortalı sayılırlar ve bunlardan bakmakla yükümlü olunan kişi durumunda olmayanlar hakkında ayrıca genel sağlık sigortası hükümleri uygulanır (Sosyal Sigortalar ve Genel Sağlık Sigortası Kanunu [SSGSSK], 2006: madde $5 / b$ ).

5 inci maddenin (b) bendinde belirtilen aday çırak, çırak ve işletmelerde meslekî eğitim görenler ile meslek liselerinde (...)(2) staja tâbi tutulan öğrenciler için Milli Eğitim Bakanlığı veya bu öğrencilerin eğitim gördükleri okullar, kamu kurum ve kuruluşları tarafından desteklenen projelerde görevli bursiyerler için projenin yürütüldüğü kamu kurum ve kuruluşları, özel sektör kuruluşları ve üniversiteler, yükseköğrenim sırasında (...)(2) staja tâbi tutulan öğrenciler için öğrenim gördükleri yükseköğretim kurumu, prim ödeme yükümlüsüdür (SSGSSK, 2006: madde 87/e). 
5510 sayılı Sosyal Sigortalar ve Genel Sağlık Sigortası Kanunu kapsamında, öğrencilerin sigorta primleri öğrenim gördükleri kurumlar tarafından karşılandığı için, öğrenciler staja kabul edilmeleri konusunda devlet tarafından desteklenmektedirler.

\subsection{Stajyer Seçimi (Ön Eleme)}

Çok sayıda organizasyonun yer aldığı günümüz pazarlarında en önemli rekabet aracı, organizasyonların sahip oldukları kaynakların etkin kullanılabilmesidir. Bu kaynakların başında ise insan kaynakları gelmektedir. Bir organizasyonun insan kaynakları yönetimi süreci, iş analizi, iş tanımları ve iş gerekleri ile şekillenir; planlamayla başlar ve dinamik bir fonksiyon olarak iş gören bulma ve seçmeyle devam eder (Bayraktaroğlu, 2015: 65).

İyi seçilmiş personel, organizasyonun amaçlarına yönelik faaliyetlerin yapılması, sürdürülmesi ve diğer kaynakların etkin kullanılması açısından oldukça önemlidir (Erenel, 2012: 14). Çünkü seçim işlemiyle verilecek olan karar yalnızca işe alınacak çalışanı değil, içinde bulunduğu sistemi de etkileyecektir. Personel seçimi, işe alınması durumunda hangi çalışanın şirket yapısına daha fazla yarar sağlayacağını tahmin etme etkinliğidir. Bu süreçte amaç, iş tanımında arzu edilen ile çalışanın bu beklentilere cevap verebilme potansiyeli arasındaki ilişkiyi bulmaktır. Adayların kişilikleri, aldıkları eğitim, yetenekleri, tecrübeleri ve ilgi duydukları konular bu ilişkiyi irdeleme adına önemli ölçütlerdir. Dikkate alınan değerlendirme ölçütleri çerçevesinde, başvuran adaylar arasında işin gerektirdiği niteliklere en uygun olanının belirlenmesi gereklidir (Adıgüzel, 2009).

Stajyer seçimi, işletmelerin bu konuya ne denli ciddi baktıklarına göre değişmekle beraber kurumsal işletmelerde belirli bir süreci oluşturan aşamalardan oluşmaktadır. Bu nedenle sektöründe lider kurumsal firmaların insan kaynakları çalışanlarından karar verme yetkisine sahip yetkililer ile gerçekleştirilen görüşmelerde Şekil 1'deki gibi bir süreç için mutabık olunmuştur.

Şekil 1: Stajyer Adaylarının Özgeçmişleri Arasından Seçimi İ̧̧ Akışı

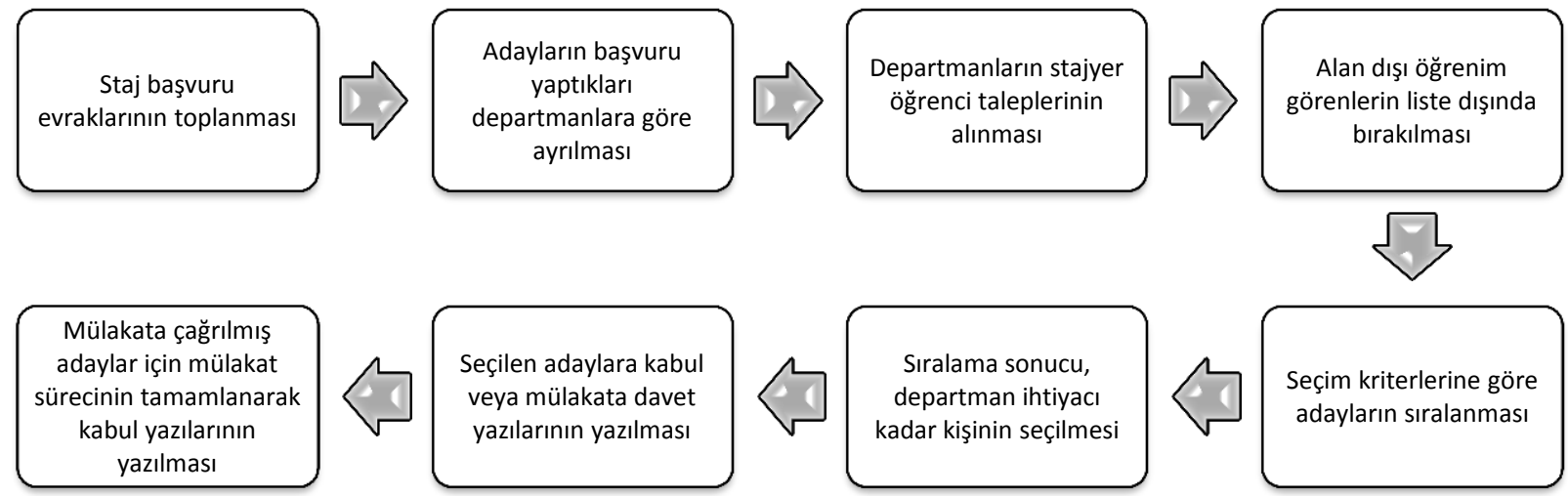

\section{VERI VE YÖNTEM}

\section{1. Çok Kriterli Karar Verme}

Yöneticilerin en temel problemi, doğru ve zamanında karar vermektir. İşletmelerde alt, orta ve üst kademe yöneticileri, kısa, orta ve uzun dönemde stratejik, taktik ve operasyonel birçok karar vermek durumundadır. Doğru ve zamanında karar verebilmek işletmeye önemli avantajlar sağlar. Ancak bu kararların alınması o kadar kolay olmayabilir. Bu konuda yöneticilerin eğitim, tecrübe ve danıştığı çevrelerinin yanında karar vermede kullandıkları yöntemleri doğru seçmesi ve uygulaması da oldukça önemlidir (Gavcar ve diğerleri, 2011: 14-15).

Karar verme, karar organının değişik seçeneklerle karşı karşıya bulunduğu durumlarda bu seçenekler arasından amaca en uygun olanını seçmedir (Tekin, 2008: 20). Bir kararın iyi veya kötü olması, erişilebilen verilere, muhtemel alternatiflere ve karar vermek için kullanılan yol/yöntem/kriterlere bağılır (Timor, 2010: 1). Karar verme süreci ise, Şekil 2'de özetlenen adımlar izlenerek yürütülür (Erdem, 2013: 18; Hillier ve Lieberman, 2001: 749-752). 
Şekil 2: Karar Verme Süreci

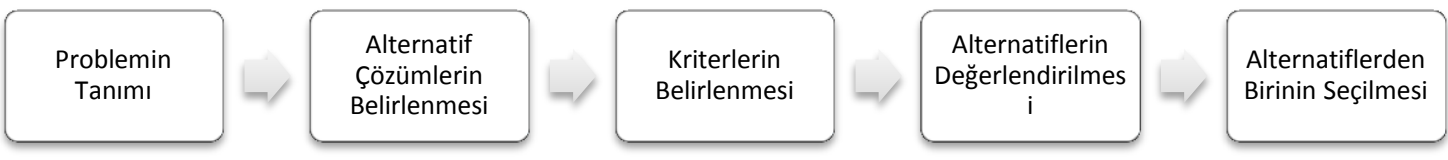

Günümüzde gerek bireysel, gerekse daha büyük ölçekli kararlar almak zorunda olan insanlar, aldıkları kararlarda birden fazla kriteri dikkate alarak hareket etmek durumundadır. Çok kriterli karar verme yönetim, matematik, psikoloji, enformatik, ekonomi ve sosyal bilimler gibi birden çok disiplinin bir araya gelip karar alıcıya birden fazla boyutla karar problemini değerlendirme ve karar alma imkânı sağlayan yöntemlerin bir araya getirildiği bir yapıdır (Yıldırım ve Önder, 2014: 15).

\subsection{SWARA (Adım Adım Ağırlık Değerlendirme Oran Analizi) Yöntemi}

Çok kriterli karar verme yöntemleri arasında yer alan ve son zamanlarda sıklıkla kullanılmaya başlanan SWARA yöntemi, ilk olarak Keršuliene, Zavadskas ve Turskis (2010) tarafından ortaya konulmuştur. SWARA yöntemi, mevcut çevresel ve ekonomik durumları dikkate alan karar vericilere kendi önceliklerini seçme konusunda fırsat tanımaktadır. Ayrıca karar verici olarak belirlenen uzmanların rolü bu yöntemde daha da önemlidir (Zolfani ve Saparauskas, 2013). SWARA yöntemi ile ilgili literatür incelendiğinde Tablo 1'de gösterilen birçok problemin çözümünde kullanıldığı bilgisi ile karşılaşılmıştır.

Tablo 1: SWARA Yöntemi Literatür Taraması

\begin{tabular}{ll}
\hline Kaynakça & Çalışma içeriği \\
\hline Keršuliene vd., (2010) & Uyuşmazlık çözümü \\
\hline Keršulienė ve Turskis, (2011) & Mimar seçimi \\
\hline Zolfani vd., (2013) & Optimal mekanik havalandırma alternatifinin seçimi \\
\hline Alimardani vd., (2013) & Tedarikçi seçimi \\
\hline Zolfani vd., (2013) & Ürün dizaynı \\
\hline Aghdaie vd., (2013) & Makine parçası seçimi \\
\hline Zolfani ve Saparauskas, (2013) & Enerjide sürdürülebilirlik göstergelerini önceliklendirme \\
\hline Zolfani ve Banihashemi, (2014) & Personel seçimi \\
\hline Zolfani ve Bahrami, (2014) & Yatırım önceliklendirme \\
\hline Vafaeipour vd., (2014) & Güneş enerji santrallerinin kurulacağı bölgenin seçimi \\
\hline Aghdaie vd., (2014a) & Tedarikçi kümeleme ve sıralama \\
\hline Aghdaie vd., (2014b) & Satış şubesi seçimi \\
\hline Dehnavi vd., (2015) & Bölgesel heyelan tehlikesinin değerlendirilmesi \\
\hline Karabasevic vd., (2015) & Işe alınacak maden mühendisi adaylarının seçimi \\
\hline Stanujkic vd., (2015) & Personel seçimi \\
\hline Stanujkic vd., (2015) & Paket tasarımı seçimi \\
\hline Karabasevic vd., (2016) & Personel seçimi \\
\hline Tuş Işık ve Aytaç Adalı, (2016) & Otel seçimi \\
\hline Çakır, (2016a) & Yazılım seçimi \\
\hline Çakır, (2016b) & Müteahhit seçimi \\
\hline
\end{tabular}


Şekil 3: SWARA Yöntemi ile Kriter Ağırlıklarının Belirlenmesi

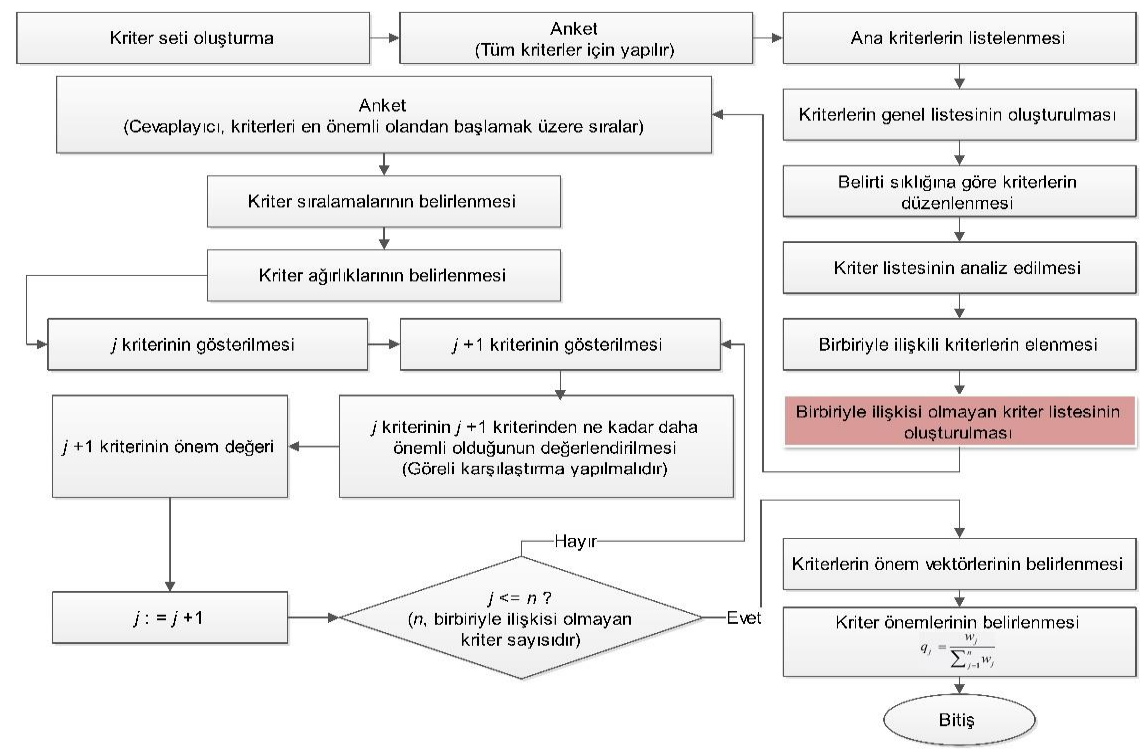

Şekil 1'de, SWARA yöntemi ile yapılan kriter ağırlıklandırma işleminin geniş çaplı iş akışı görülebilir. Yöntemde değerlendirmeye alınacak kriterlerin (Şekil 3'Teki "Birbiriyle ilişkisi olmayan kriter listesinin oluşturulması" adımı) belirlenmesi durumunda ise, aşağıda yer alan 5 adımda kriter ağılıkları belirlenebilmektedir.

Adım 1: Kriterler en önemliden başlamak üzere sıralanır.

Adım 2: İkinci kriterden başlayarak, her bir kriter için göreli önem düzeyleri belirlenir. Bunun için, j kriteri ile bir önceki kriter (j-1) karşılaştıııır. Kerseliene vd. (2010), bu orana "ortalama değerin karşılaştırmalı önemi” olarak adlandırmış ve sj simgesi ile göstermişlerdir.

Adım 3: Katsayı (kj) aşağıdaki eşitlikle belirlenir:

$$
k_{j}=\left\{\begin{array}{cc}
1 & j=1 \\
s_{j}+1 & j>1
\end{array}\right.
$$

Adım 4: Önem vektörü $w_{j}$, aşağıda yer alan eşitlikle hesaplanır:

$$
w_{j}=\left\{\begin{array}{cc}
1 & j=1 \\
\frac{x_{j-1}}{k_{j}} & j>1
\end{array}\right.
$$

Adım 5: Kriterlere ait ağırlıkların $\left(q_{j}\right)$ hesaplama işlemi ise, aşağıdaki eşitlikle sağlanır:

$$
q_{j}=\frac{w_{j}}{\sum_{k=1}^{n} w_{k}}
$$

qj, j kriterinin göreli önemini göstermektedir. 


\section{BULGULAR VE TARTIŞMA}

Uygulamada öncelikle kriterler belirlenerek, SWARA yöntemiyle bu kriterler ağırlıklandırılmıştır.

\subsection{Stajyerlerin Seçiminde Rol Oynayan İnsan Kaynakları Çalışanlarının Belirlenmesi}

Kurumsal işletmelerin insan kaynakları departmanında genel olarak hiyerarşik yapılanma üstten alta doğru sırasıyla; insan kaynakları müdürü veya koordinatörü, insan kaynakları uzmanı veya şefi, insan kaynakları uzman yardımcısı veya şef yardımcısı, insan kaynakları elemanı veya memuru ve insan kaynakları stajyeri olarak Şekil 4'teki gibi sıralanabilir.

\section{Şekil 4: Insan Kaynakları Departmanında Çalışan Hiyerarşisi}

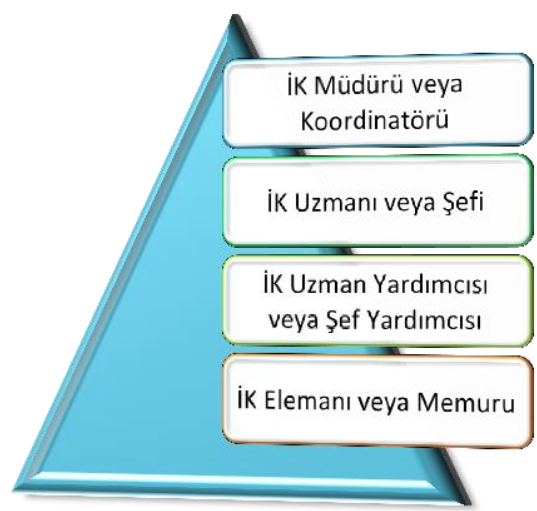

Özellikle stajyer seçimlerinde mümkün olduğu kadar insan kaynakları elemanı veya memuru ile insan kaynakları uzman yardımcısı veya şef yardımcısına, üstleri tarafından yetki göçerimi yapılarak iş başında öğrenmelerini sağlayacak eğitim verilmiş olur. Personel seçiminde karşılaşılabilecek veya dikkat edilmesi gereken hususların, bir ön çalışma niteliğinde olan stajyer adaylarının değerlendirilmesi faaliyeti, bu çalışanların eğitimleri için önemli bir fırsat olmaktadır. Bu nedenle çalışma, kurumsal işletmelerde çalışan insan kaynakları uzman yardımcısı veya şef yardımcısı ile insan kaynakları elemanı veya memuru olan çalışanlar ile yürütülmüştür.

\subsection{Stajyerlerin Seçiminde Kullanılacak Kriterlerin Belirlenmesi}

Ülkemizdeki kurumsal firmaların birçoğu staj başvurularını internetten kabul etmekte ve bunun için kariyer.net, yenibiris.com, secretcv.com gibi web sitelerini tercih etmektedir. Bu sitelerde oluşturulan özgeçmişler incelendiğinde, değerlendirmeye alınabilecek kriterler, stajyer başvurusu için elendiğinde Tablo 2'deki şekilde sıralanabilir.

Tablo 2: Stajyer Seçim Kriterleri

\begin{tabular}{ll}
\hline$C_{1}$ & Stajyer Adayının Genel Görünümü (Yaş, fiziksel görünüm vs.) \\
\hline$C_{2}$ & Stajyer Adayının İkametgâhı (İşyerine yakın olması) \\
\hline$C_{3}$ & Stajyer Adayının İş Tecrübesi (Daha önceki stajyerlikleri gibi) \\
\hline$C_{4}$ & Stajyer Adayının İnsan Kaynakları Yönetimi Önlisans Programındaki Başarı Durumu \\
\hline$C_{5}$ & Stajyer Adayının Yabancı Dil Bilgisi \\
\hline$C_{6}$ & Stajyer Adayının Bilgisayar (Office Programları vs.) Bilgisi \\
\hline$C_{7}$ & Stajyer Adayının Referansları \\
\hline$C_{8}$ & Stajyer Adayının İşe Uygunluğu \\
\hline$C_{9}$ & Stajyer Adayının Staj Yapma İsteğindeki Davranışı
\end{tabular}

\subsection{Stajyerlerin Seçiminde Kullanılacak Kriterlerin Ağırlıklarının Hesaplanması}

Tablo 2'deki değerlendirme kriterlerinin önem düzeylerinin belirlenebilmesi için, on dört karar verici seçilmiştir. Öncelikle, SWARA yönteminin ilk adımı olan kriterlerin en önemliden en az önemliye sıralanması işlemi her bir karar verici tarafından 
ayrı ayrı yapılmıştır. Karar vericilerin insan kaynakları uzman yardımcısı veya insan kaynakları memuru olmasından dolayı, çalışmanın geri kalanında "uzman" olarak adlandırılacaklardır. Sıralama sonuçları Tablo 3'te gösterilmiştir. Tabloya göre, Uzman $1\left(\mathrm{UZ}_{1}\right)$ için en önemli kriterin " $C_{2}$ - Stajyer Adayının ikametgâhı (İşyerine yakın olması)" kriteri olduğu görülebilmektedir.

Tablo 3: Karar Vericilere Göre Kriter Sıralamaları

\begin{tabular}{ccccccccccccccc}
\hline & $\mathbf{U Z}_{1}$ & $\mathbf{U Z}_{2}$ & $\mathbf{U Z}_{3}$ & $\mathbf{U Z}_{4}$ & $\mathbf{U Z}_{5}$ & $\mathbf{U Z}_{6}$ & $\mathbf{U Z}_{\mathbf{7}}$ & $\mathbf{U Z}_{8}$ & $\mathbf{U Z}_{9}$ & $\mathbf{U Z}_{10}$ & $\mathbf{U Z}_{11}$ & $\mathbf{U Z}_{12}$ & $\mathbf{U Z}_{13}$ & $\mathbf{U Z}_{14}$ \\
\hline $\mathrm{C}_{1}$ & 3 & 9 & 9 & 4 & 1 & 1 & 8 & 8 & 8 & 3 & 2 & 1 & 2 & 8 \\
\hline $\mathrm{C}_{2}$ & 1 & 8 & 5 & 9 & 2 & 6 & 9 & 9 & 9 & 8 & 1 & 4 & 1 & 9 \\
\hline $\mathrm{C}_{3}$ & 7 & 3 & 1 & 5 & 9 & 4 & 2 & 4 & 4 & 7 & 7 & 8 & 9 & 2 \\
\hline $\mathrm{C}_{4}$ & 2 & 4 & 2 & 6 & 8 & 5 & 3 & 7 & 3 & 4 & 6 & 5 & 5 & 3 \\
\hline $\mathrm{C}_{5}$ & 6 & 5 & 6 & 7 & 7 & 8 & 7 & 3 & 6 & 5 & 8 & 7 & 7 & 7 \\
\hline $\mathrm{C}_{6}$ & 5 & 6 & 3 & 3 & 6 & 7 & 6 & 6 & 5 & 6 & 5 & 6 & 6 & 6 \\
\hline $\mathrm{C}_{7}$ & 4 & 7 & 8 & 8 & 4 & 9 & 5 & 5 & 7 & 9 & 9 & 9 & 8 & 5 \\
\hline $\mathrm{C}_{8}$ & 9 & 1 & 4 & 2 & 3 & 2 & 1 & 2 & 1 & 2 & 4 & 3 & 4 & 1 \\
\hline $\mathrm{C}_{9}$ & 8 & 2 & 7 & 1 & 5 & 3 & 4 & 1 & 2 & 1 & 3 & 2 & 3 & 4
\end{tabular}

Tablo 3'te yer alan kriterler, en önemli olan ilk sırada olmak üzere Tablo 4'deki gibi sıralanmış ve ikinci kriterden itibaren her bir kriter için göreli önem düzeyleri $\left(s_{j}\right)$ uzmanlar tarafından ayrı ayrı belirlenmiştir. Örneğin, Uzman 1 için $\mathrm{C}_{2}$ kriteri ile $\mathrm{C}_{4}$ kriteri arasında karşılaştırmalı önem düzeyi 0,20'dir.

Tablo 4: Kriterlerin Uzmanlar Düzeyinde Karşılaştırmalı Önemi

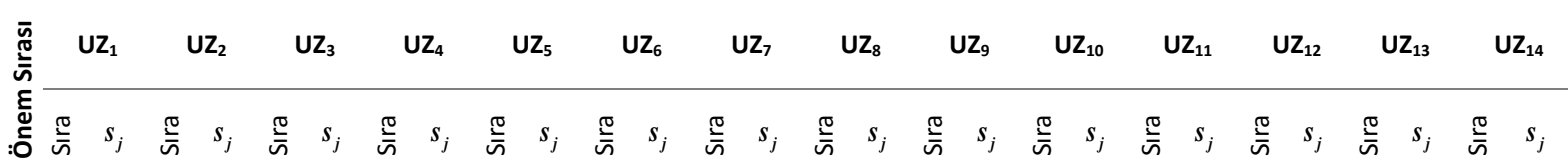

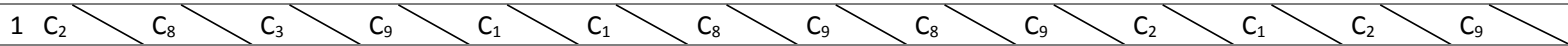
$\begin{array}{lllllllllllllllllllllllllllll}2 & C_{4} & 0,20 & C_{9} & 0,05 & C_{4} & 0,85 & C_{8} & 0,10 & C_{2} & 1,00 & C_{8} & 0,70 & C_{3} & 0,20 & C_{8} & 0,30 & C_{9} & 0,60 & C_{8} & 0,90 & C_{1} & 1,00 & C_{9} & 0,15 & C_{1} & 1,00 & C_{7} & 0,20\end{array}$ $\begin{array}{lllllllllllllllllllllllllllll}3 & C_{1} & 0,20 & C_{3} & 0,20 & C_{6} & 0,20 & C_{6} & 0,70 & C_{8} & 0,60 & C_{9} & 0,90 & C_{4} & 0,15 & C_{5} & 0,30 & C_{4} & 0,60 & C_{1} & 0,75 & C_{9} & 0,20 & C_{8} & 0,25 & C_{9} & 0,70 & C_{8} & 0,30\end{array}$ $\begin{array}{lllllllllllllllllllllllllllll}4 & C_{7} & 0,10 & C_{4} & 0,25 & C_{8} & 0,05 & C_{1} & 0,20 & C_{7} & 0,90 & C_{3} & 0,80 & C_{9} & 0,10 & C_{3} & 0,70 & C_{3} & 0,60 & C_{4} & 0,85 & C_{8} & 0,60 & C_{2} & 0,05 & C_{8} & 0,90 & C_{1} & 0,10\end{array}$ $\begin{array}{lllllllllllllllllllllllllllll}5 & C_{6} & 0,05 & C_{5} & 0,05 & C_{2} & 0,35 & C_{3} & 0,20 & C_{9} & 1,00 & C_{4} & 0,70 & C_{7} & 0,10 & C_{7} & 0,30 & C_{6} & 0,60 & C_{5} & 0,65 & C_{6} & 0,20 & C_{4} & 0,05 & C_{4} & 0,75 & C_{4} & 0,25\end{array}$ $\begin{array}{lllllllllllllllllllllllllllll}6 & C_{5} & 0,05 & C_{6} & 0,20 & C_{5} & 0,05 & C_{4} & 0,50 & C_{6} & 0,50 & C_{2} & 0,60 & C_{6} & 0,10 & C_{6} & 0,30 & C_{5} & 0,50 & C_{6} & 0,75 & C_{4} & 0,05 & C_{6} & 0,40 & C_{6} & 0,80 & C_{6} & 0,30\end{array}$ $\begin{array}{lllllllllllllllllllllllllllll}7 & C_{3} & 0,05 & C_{7} & 0,15 & C_{9} & 0,50 & C_{5} & 0,10 & C_{5} & 1,00 & C_{6} & 0,60 & C_{5} & 0,05 & C_{4} & 0,30 & C_{7} & 0,65 & C_{3} & 0,55 & C_{3} & 0,50 & C_{5} & 0,30 & C_{5} & 0,95 & C_{2} & 0,20\end{array}$ $\begin{array}{lllllllllllllllllllllllllllll}8 & C_{9} & 0,05 & C_{2} & 0,40 & C_{7} & 0,90 & C_{7} & 0,50 & C_{4} & 0,80 & C_{5} & 0,60 & C_{1} & 0,05 & C_{1} & 0,30 & C_{1} & 0,30 & C_{2} & 0,90 & C_{5} & 0,70 & C_{3} & 0,10 & C_{7} & 0,70 & C_{3} & 0,80\end{array}$ \begin{tabular}{lllllllllllllllllllllllllllll}
\hline & $C_{8}$ & 0,05 & $C_{1}$ & 0,05 & $C_{1}$ & 0,10 & $C_{2}$ & 0,50 & $C_{3}$ & 0,70 & $C_{7}$ & 0,60 & $C_{2}$ & 0,05 & $C_{2}$ & 0,20 & $C_{2}$ & 0,90 & $C_{7}$ & 0,60 & $C_{7}$ & 0,05 & $C_{7}$ & 0,30 & $C_{3}$ & 0,65 & $C_{5}$ & 0,35
\end{tabular} SWARA yöntemiyle yapılan kriter ağırlıklandırma adımları ise, şu şekilde devam etmektedir;

Öncelikle, Eşitlik 1 ile $s_{j}$ 'ler kullanılarak, katsayı $\left(k_{j}\right)$ değerlerine ulaşılmıştır. Ardından Eşitlik 2 yardımıyla, her bir kritere ait önem vektör $\left(w_{j}\right)$ değerleri hesaplanmıştır. Son olarak, kriterlere ait ağırlıklar $\left(q_{j}\right)$ Eşitlik 3 ile hesaplanmıştır. Uzman 1'e ait her bir kriter için hesaplanan $k_{j}, w_{j}$ ve $q_{j}$ değerleri Tablo 5 'te gösterilmiştir.

Tablo 5: SWARA Yöntemi ile Uzman 1'e Ait Kriter Ağırlıklarını Hesaplama İşlemi

\begin{tabular}{cccccc}
\hline Siralama & Kriterler & $\boldsymbol{s}_{\boldsymbol{j}}$ & $\boldsymbol{k}_{\boldsymbol{j}}$ & $\boldsymbol{w}_{\boldsymbol{j}}$ & $\boldsymbol{q}_{\boldsymbol{j}}$ \\
\hline $\mathbf{1}$ & $\mathrm{C}_{2}$ & 1,00 & 1,00 & 0,170 \\
\hline $\mathbf{2}$ & $\mathrm{C}_{4}$ & 0,20 & 1,20 & 0,833 & 0,141 \\
\hline $\mathbf{3}$ & $\mathrm{C}_{1}$ & 0,20 & 1,20 & 0,694 & 0,118 \\
\hline $\mathbf{4}$ & $\mathrm{C}_{7}$ & 0,10 & 1,10 & 0,631 & 0,107 \\
\hline $\mathbf{5}$ & $\mathrm{C}_{6}$ & 0,05 & 1,05 & 0,601 & 0,102 \\
\hline $\mathbf{6}$ & $\mathrm{C}_{5}$ & 0,05 & 1,05 & 0,573 & 0,097 \\
\hline $\mathbf{7}$ & $\mathrm{C}_{3}$ & 0,05 & 1,05 & 0,545 & 0,093 \\
\hline $\mathbf{8}$ & $\mathrm{C}_{9}$ & 0,05 & 1,05 & 0,519 & 0,088 \\
\hline $\mathbf{9}$ & $\mathrm{C}_{8}$ & 0,05 & 1,05 & 0,495 & 0,084 \\
\hline
\end{tabular}


Tablo 5'te, Uzman 1'den elde edilen veriler için yapılan hesaplamaların diğer uzmanlardan elde edilen veriler için de yapılması sonucu elde edilen kriter ağırlıkları Tablo 6’ya çıkarılmıştır.

Tablo 6: Kriterlerin Uzmanlar Bazında Hesaplanan Ağırlıkları

\begin{tabular}{|c|c|c|c|c|c|c|c|c|c|c|c|c|c|c|}
\hline Kriterle & $\mathrm{UZ}_{1}$ & $\mathrm{UZ}_{2}$ & $\mathrm{UZ}_{3}$ & $\mathrm{UZ}_{4}$ & $\mathrm{UZ}_{5}$ & $\mathrm{UZ}_{6}$ & $\mathrm{UZ}_{7}$ & $\mathrm{UZ}_{8}$ & $\mathrm{UZ}_{9}$ & $\mathrm{UZ}_{10}$ & $\mathrm{UZ}_{11}$ & $\mathrm{UZ}_{12}$ & $\mathrm{UZ}_{13}$ & $U_{14}$ \\
\hline$C_{1}$ & 0,118 & 0,054 & 028 & 0,112 & 0,462 & 0,432 & 0,085 & 0,034 & 0,018 & 0,136 & 0,173 & 0,192 & 0,234 & 0,130 \\
\hline$C_{2}$ & & & & ( & & & & & & & & & 8 & 57 \\
\hline 3 & & & & & & & & & & & & & & \\
\hline$C_{4}$ & 10 & 115 & 7 & 0,06 & & & & & & & & & & \\
\hline$C_{5}$ & & 0 & 088 & 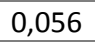 & & 0 & 9 & & & & 0 & 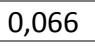 & & 8 \\
\hline$C_{6}$ & & 091 & 131 & 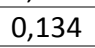 & 0,025 & & 93 & 8 & 8 & 5 & 75 & 36 & & 080 \\
\hline$C_{7}$ & - & 07 & 0, & 0 & 0 & & 0,103 & & 0,023 & 0 , & 0,027 & & &, 186 \\
\hline$C_{8}$ & & & & 0,228 & & 0,254 & 0,171 & 0,216 & & & 0,090 & & & 0,143 \\
\hline$C_{9}$ & 0,088 & 0,172 & 0,059 & 0,251 & 0,038 & 0,134 & 0,113 & 0,281 & 0,236 & 0,452 & 0,144 & 0,167 & 0,138 & 0,224 \\
\hline
\end{tabular}

Her bir uzmana ait kriter ağırlıklarının ortalamasının alınması sonucu elde edilen kriter ağırıkları ise, Tablo 7'de gösterilmiştir. İnsan Kaynakları uzmanlarının değerlendirmeleri sonucunda, en önemli kriterin 0,178 değeriyle " $\boldsymbol{C}_{\boldsymbol{g}}$ - Stajyer Adayının Staj Yapma isteğindeki Davranışı" kriteri olduğu sonucuna ulaşılmışır.

Tablo 7: Nihai Kriter Ağırlıkları ve Sıralama

\begin{tabular}{llcc}
\hline & \multicolumn{1}{c}{ Kriterler } & Nihai Kriter Ağırlı̆ı & Sıralama \\
\hline $\mathbf{C}_{\mathbf{1}}$ & Stajyer Adayının Genel Görünümü/ilk İzlenimi & 0,158 & 3 \\
\hline $\mathbf{C}_{\mathbf{2}}$ & Stajyer Adayının İkamet Ettiği Yer & 0,124 & 4 \\
\hline $\mathbf{C}_{\mathbf{3}}$ & Stajyer Adayının Çalışma Geçmişi & 0,085 & 6 \\
\hline $\mathbf{C}_{\mathbf{4}}$ & Stajyer Adayının IK Yönetimi Önlisans Programındaki Başarı Durumu & 0,089 & 5 \\
\hline $\mathbf{C}_{5}$ & Stajyer Adayının Yabancı Dil Bilgisi & 0,060 & 8 \\
\hline $\mathbf{C}_{6}$ & Stajyer Adayının Bilgisayar Bilgisi & 0,071 & 7 \\
\hline $\mathbf{C}_{\mathbf{7}}$ & Stajyer Adayının Referansları & 0,058 & 9 \\
\hline $\mathbf{C}_{\mathbf{8}}$ & Stajyer Adayının İşe Uygunluğu & 0,176 & 2 \\
\hline $\mathbf{C}_{9}$ & Stajyer Adayının Staj Yapma İsteğindeki Davranışı & 0,178 & 1 \\
\hline
\end{tabular}

\section{SONUÇ}

Çalışma sonucunda, önlisans öğrencilerinin staja kabul edilmesinde en önemli ilk üç kriter:

i. Stajyer adayının staj yapma isteğindeki davranışı,

ii. Stajyer adayının işe uygunluğu

iii. Stajyer adayının genel görünümü/ilk izlenimi,

şeklinde sıralanmaktadır.

Genel olarak önlisans öğrencilerinin, staj yapma konusundaki istekliliğinin düşük seviyelerde kalması ve stajı bir zorunluluk olarak görmeleri, staja kabul edilmeleri konusundaki en büyük engel olarak görülmektedir. Yine ilk izlenim veya genel görünüm ile ilgili olarak öğrencilerin mülakat konusunda tecrübesiz olması, staja kabul edilmeleri önünde önemli bir engel oluşmaktadır.

Stajyer adayın işe uygunluğu konusundaki kriter ise sadece öğrenci tarafından şekillendirilen bir kriter olmadığı için, önlisans eğitimleri sırasında akademik danışmanları veya ders aldıkları öğretim elemanları tarafından şekillendirilmektedir. Bu nedenle insan kaynakları programının akademik danışmanı veya bu programda ders veren öğretim elemanlarının da kriterleri sıralaması ve ağılıklandırması sağlanarak, akademisyenler tarafından kariyerleri ve dolayısıyla işe uygunlukları şekillendirilen öğrencilerin, sektörün taleplerini ne kadar karşıladığı konusunda fikir edinilebilir.

Çalışma konusunun, insan kaynakları önlisans öğrencilerinin stajyer adaylıkları konusunda kısıtı tutulmayıp diğer önlisans program veya lisans bölümleri için de uygulanması, sektörün stajyer adaylarından beklentilerinin belirlenerek, öğrencilerin 
daha sağııkı kariyer planlamasına katkıda bulunması sağlanabilir. Hatta elde edilen bulgular ışı̆̆ında, akademisyenlerin stajyer adayı öğrencilerini, staj değerlendirilmesine hazırlaması sağlanabilir.

Çalışma konusunun, sadece stajyer adaylarına değil aynı zamanda iş başvurusu yapan çalışan adaylarına da farklı sektörlerde uygulanması, uygun işe uygun kişi seçimi konusunda bir kılavuz niteliği taşıyabilir.

\section{KAYNAKLAR}

Ahmed, S. U., Al Mahmud, A. ve Bergaust, K. (2009). Aesthetics in Human-Computer Interaction: Views and Reviews. Lecture Notes in Computer Science içinde (C. 5610 LNCS, ss. 559-568). doi:10.1007/978-3-642-02574-7_63

App Annie \& MEF. (2014). Emerging Markets and Growth in the Global App Economy.

Baisya, R. K. ve Das, G. G. (2008). Aesthetics In Marketing. Thousand Oaks: Sage Publications, Inc.

Bauerly, M. ve Liu, Y. (2006). Computational modeling and experimental investigation of effects of compositional elements on interface and design aesthetics. Int. J. Hum.-Comput. Stud., 64(8), 670-682.

Boyatzis, C. J. ve Varghese, R. (1994). Children's emotional associations with colors. The Journal of genetic psychology. doi:10.1080/00221325.1994.9914760

Burdge, B. (2014). New Research Shows Mobile Dominates Desktops. Movablelnk. http://blog.movableink.com/new-research-showsmobile-dominates-desktops-with-65-of-total-email-opens-in-q4-2013/ adresinden erişildi.

Cai, S. ve Xu, Y. (2011). Designing Not Just for Pleasure: Effects of Web Site Aesthetics on Consumer Shopping Value. International Journal of Electronic Commerce, 15(4), 159-188. doi:10.2753/JEC1086-4415150405

Carare, O. (2012). The impact of bestseller rank on demand: Evidence from the app market. International Economic Review, 53(3), 717742. doi:10.1111/j.1468-2354.2012.00698.x

Carmines, E. G. ve Zeller, R. A. (1979). Reliability and Validity Assessment. Sage University Papers Series. Beverly Hills, California: Sage Publications.

Chaudhari, A. (2015). Mobile Applications Market to Soar. Research, Transparency Market. 17 Eylül 2015 tarihinde http://www.transparencymarketresearch.com/pressrelease/mobile-applications-market.htm adresinden erişildi.

Chebat, J.-C. ve Morrin, M. (2007). Colors and cultures: Exploring the effects of mall décor on consumer perceptions. Journal of Business Research, 60(3), 189-196. doi:10.1016/j.jbusres.2006.11.003

Choi, J. H. ve Lee, H. J. (2012). Facets of simplicity for the smartphone interface: A structural model. International Journal of Human Computer Studies, 70(2), 129-142. doi:10.1016/j.ijhcs.2011.09.002

ComScore. (2014). The US Mobile App Report.

Countryman, C. C. ve Jang, S. (2006). The effects of atmospheric elements on customer impression: the case of hotel lobbies. International Journal of Contemporary Hospitality Management, 18(7), 534-545. doi:10.1108/09596110610702968

Creusen, M. E. H., Veryzer, R. W. ve Schoormans, J. P. L. (2010). Product value importance and consumer preference for visual complexity and symmetry. European Journal of Marketing, 44(9/10), 1437-1452. doi:10.1108/03090561011062916

Cyr, D. (2008). Modeling Web Site Design Across Cultures: Relationships to Trust, Satisfaction, and E-Loyalty. Journal of Management Information Systems, 24(4), 47-72. doi:10.2753/MIS0742-1222240402

Degeratu, A. M., Rangaswamy, A. ve Wu, J. (2000). Consumer choice behavior in online and traditional supermarkets: The effects of brand name, price, and other search attributes. International Journal of Research in Marketing, 17(1), 55-78. doi:10.1016/S0167-8116(00)000057

Donovan, R. J. ve Rossiter, J. R. (1982). Store Atmosphere: An Environmental Psychology Approach. Journal of Retailing, 58(1), 34. doi:Article

Donovan, R. J., Rossiter, J. R., Marcoolyn, G. ve Nesdale, A. (1994). Store atmosphere and purchasing behavior. Journal of Retailing, (70), 283-94.

Eroglu, S. a., Machleit, K. a. ve Davis, L. M. (2003). Empirical Testing of a Model of Online Store Atmospherics and Shopper Responses. Psychology \& Marketing, 20(2), 99-121. doi:10.1002/mar.

Fornell, C. ve Larcker, D. F. (1981). Evaluating Structural Equation Models with Unobservable Variables and Measurement Error. Journal of Marketing Research (JMR), 18(1), 39-50. 